\title{
Historia y clima en México: perspectivas y horizontes desde la historiografía
}

\author{
Història i clima a Mèxic: perspectives \\ $i$ horitzons des de la historiografia \\ History and climate in Mexico: perspectives \\ and horizons from the historiography
}

Luis Alberto Arrioja Díaz Viruel/ ${ }^{1}$

A mi maestro y amigo Juan Manuel Pérez Zevallos

In memoriam

\section{Resumen}

En este artículo se examina el devenir de la historiografía dedicada al clima en México, las perspectivas y herramientas analíticas que han planteado y - sobre todo- los horizontes de trabajo que se han definido en los últimos cincuenta años. A lo largo de sus páginas se plantean los diferentes derroteros que han seguido estos estudios, sus contribuciones conceptuales y metodológicas, y sus vínculos disciplinarios.

Palabras clave: clima, climatología histórica, historia del clima, variabilidad climática, desastres.

\section{Resum}

En aquest article s'examina l'esdevenir de la historiografia dedicada al clima a Mèxic, les perspectives i eines analítiques que han plantejat $\mathrm{i}$-sobretot- els horitzons de treball que s'han definit en els darrers cinquanta anys. Al llarg de les seves planes es plantegen els diferents camins que han seguit els estudis, les seves contribucions conceptuals i metodològiques i els seus vincles disciplinaris.

1.. ORCID: 0000-0002-0182-7072. El Colegio de Michoacán (México).Correo electrónico: larrioja@colmich.edu.mx. Recibido: IV/2021. Evaluado: VI/2021. Versión definitiva: VII/2021

Este artículo forma parte del proyecto HAR2017-82810-P, incluido en el Plan Estatal de Fomento de la Investigación Científica y Técnica de Excelencia promovido por el Ministerio de Ciencia, Innovación y Universidades (Gobierno de España), la Agencia Estatal de Investigación y los Fondos FEDER. Agradezco los comentarios y sugerencias de los evaluadores anónimos, así como el diálogo permanente con Armando Alberola Romá y Virginia García Acosta. 
Paraules clau: clima, climatologia històrica, historia del clima, variabilitat climàtica, desastres.

\begin{abstract}
This article examines the evolution of the historiography dedicated to the climate in Mexico, the perspectives and analytical tools proposed, the conceptual and methodological contributions, and their disciplinary links and scope over the last 50 years.
\end{abstract}

Keywords: Weather, historical climatology, climate history, climate variability, disaster.

\title{
Introducción
}

Hace un par de décadas, el arqueólogo Brian Fagan advirtió que «historia» y «clima» son voces indisolubles que se distinguen por incidir directamente en el entorno humano y físico, y por estar estrechamente vinculadas a procesos de sobrevivencia y adaptación de especies. Inclusive, señaló que estos procesos posibilitaron que hombres, animales y plantas desarrollaran estrategias para enfrentar sequías prolongadas, lluvias excesivas, calores sofocantes, fríos intensos y plagas devastadoras durante la denominada Pequeña Edad de Hielo (PEH 1350-1880 d. C.) (Fagan 2008: 15-17). A juzgar por la experiencia americana, hoy en día, los indicios de este pasado climático se conservan con mayor proporción para el período 1521 y 1880: expedientes sobre sequías y hambrunas; crónicas sobre inundaciones, tormentas de nieve y paisajes desolados; relatos sobre desaparición de torrentes, formación de bancos de sal y reorientación de corrientes; así como informes sobre tempestades, plagas biológicas, escasez de alimentos y brotes epidémicos (Prieto et al. 2018; García Acosta et al. 2003; Arrioja 2019). En el caso de México, un legado documental extenso ha permitido examinar los procesos acaecidos durante la $\mathrm{PEH}$ y plantear que - durante más de tres siglos- se experimentó un cambio térmico que, a su vez, supuso un descenso en las temperaturas, un enfriamiento muy heterogéneo y una serie de oscilaciones atmosféricas. Mientras que en algunos lugares estos cambios propiciaron la formación de hielos en cotas bajas y la presencia de lluvias prolongadas, en otros escenarios provocaron veranos extremadamente secos y cálidos. Prueba de ello son las lluvias intermitentes que durante el otoño de 1629 inundaron la Ciudad de México y la dejaron bajo el agua por cinco años. Asimismo, el ciclo de heladas y sequías que —entre 1785 y 1786 — afectaron el centro y occidente de Nueva España y configuraron una de las crisis de subsistencia más severas de las que se tenga conocimiento en la historia. No muy lejos de esta experiencia se encuentran las sequías de 1833 y 1853, así como las tormentas solares de 1859-1860 que generaron calores e incendios intensos en el campo mexicano. A diferencia de aquellos espacios donde el devenir del clima ha sido un asunto secundario, en México las investigaciones especializadas han contribuido a tener un conocimiento profundo y advertir horizon- 
tes de estudio sobre las relaciones que existen entre clima, naturaleza y grupos humanos. Para ello han sido fundamentales los trabajos desprendidos desde la historia, la climatología histórica y la paleoclimatología; es decir, propuestas que han analizado el clima en todas sus dimensiones - temporales y espaciales-, acumulado información sobre eventos atmosféricos, elaborado índices sobre temperaturas y precipitaciones de la etapa preinstrumental y estudiado nociones humanas sobre el clima a través del tiempo (Domínguez Castro et al. 2019). En este artículo examino el devenir de la historiografía dedicada al clima en México, las perspectivas y herramientas analíticas que han planteado, y -sobre todolos horizontes de trabajo que han definido en los últimos cincuenta años. A lo largo de estas páginas pondré en contexto al lector con los estudios históricos que han retomado el clima como un elemento de análisis y discusión. Como será fácil advertir, este artículo no pretende una reconstrucción genealógica ni exhaustiva de todos los estudios existentes, sino solo identificar aquellos que han servido como precursores o puntos de enlace ante las necesidades derivadas por las discusiones historiográficas. Tales debates han caracterizado la emergencia de nuevas propuestas analíticas, interpretativas y metodológicas en la historiografía de los siglos xx y xxi. Así, a lo largo de estas páginas se presenta una exposición de los alcances y límites que encierra el clima en la historiografía mexicana de las últimas décadas, y se pone al descubierto la manera en que una herramienta conceptual propia de las ciencias ambientales ha cobrado vigencia en los estudios históricos.

\section{Orígenes y precursores de un horizonte de trabajo}

Hoy en día, el clima ocupa un lugar preponderante en todas las sociedades al grado que su registro y estudio lo han convertido en un elemento central para la historia. Es de advertir que estas ideas no se han generado en tiempos recientes, tienen sus orígenes en el pasado remoto: la acumulación de conocimientos sobre el clima es el resultado de un largo proceso de adaptación al entorno. No obstante, entre 1660 y 1810, el racionalismo y el desarrollo científico que se apoderó de Nueva España posibilitaron que la observación y experimentación, así como el uso de instrumentos coadyuvaran en un mejor conocimiento del clima y de sus manifestaciones físicas. Durante estos años salieron a la luz algunos manuscritos apoyados en el uso de termómetros y barómetros, así como reflexiones personales sobre hidrometeoros y temperaturas en ciertas ciudades del virreinato. Todo parece indicar que las luchas de independencia y la construcción del Estado nacional impactaron negativamente en estas prácticas, al grado que México nació como un país ajeno a los avances de la ciencia moderna durante las primeras décadas del siglo xix. Dicho rezago se acentuó con la inestabilidad política y económica, y con una raquítica labor científica cuyo reflejo más evidente fue la carencia de estudios específicos. Habrá que subrayar que -durante la primera mitad del siglo xix - las contribuciones sobre el conocimiento del clima fueron escasas, unipersonales, poco sistemáticas y herederas de la tradición ilustrada (Trabulse 1985; Contreras Servín 1999; Viesca y Sanfilippo, 2010). A partir de 1860, este panorama comenzó a cambiar gracias a las labores realizadas por sociedades científi- 
cas e individuos interesados en la materia. Sin embargo, fue a partir de 1863 cuando las reflexiones profesionales cobraron dinamismo, especialmente con la creación del Observatorio Nacional; con todo, fue hasta bien entrado el Porfiriato y bajo el influjo del positivismo científico cuando estas labores se impulsaron con creces desde el Observatorio Meteorológico Central (1877). Estas iniciativas dieron como resultado una serie de mediciones instrumentales para el período 1877-1913, así como la instauración de veintiuna estaciones meteorológicas encargadas de registrar — día a día — las condiciones atmosféricas a lo largo y ancho del país (Contreras Servín 1999). Desafortunadamente, la Revolución Mexicana frustró la continuidad de estas tareas y - por ende- la implementación de proyectos relacionados con el mapa climático de México, la red de estaciones meteorológicas y la profesionalización del personal encargado de estas. No fue hasta la cuarta década del siglo xx, gracias a la estabilidad alcanzada con los gobiernos postrevolucionarios, cuando estas propuestas recobraron su curso y se institucionalizaron en varias dependencias encargadas de proveer información sobre las condiciones atmosféricas a escala nacional e identificar una serie de hidrometeoros que afectaban las actividades económicas y sociales del país.

El hecho de que existan ciento cuarenta y cuatro años de registros instrumentales del clima en México no parece demasiado en el plano histórico. De ahí la necesidad de obtener información de fuentes documentales, materiales arqueológicos y registros proxy data que ayuden a reconstruir las condiciones climáticas de períodos previos a la etapa instrumental. Cabe subrayar que un análisis integral de estas fuentes y una reflexión transdiciplinaria permitirá tener un conocimiento más profundo sobre la evolución del clima en México.

En lo que respecta a la presencia de contenidos y discusiones sobre el clima en los estudios históricos, conviene decir que — hace más de sesenta años- Emmanuel Le Roy Ladurie propuso en una serie de artículos el desarrollo de un horizonte historiográfico -bajo la influencia de la École des Annales- donde el objeto central era el clima y sus efectos en los grupos humanos, ya sea a través de la presencia de fenómenos climáticos extremos, crisis agrícolas y de subsistencia, escasez de alimentos y brotes epidémicos (Le Roy Ladurie 1960; 1961; 1963; 1965; 1967); un horizonte que —poco a poco-ganó complejidad, sumó perspectivas disciplinarias y herramientas de análisis (meteorología, biología, física, estadística, historia social, historia económica, etcétera) y construyó argumentos para explicar los procesos históricos a partir de las complejas relaciones entre el clima, el hombre, las instituciones y las ideas. Al respecto, la propuesta de Le Roy Ladurie fue contundente y ampliamente difundida: estudiar la historia a partir de descartar ideas preconcebidas, recurrir a fuentes de información diversas, articular procesos económicos y sociales en contextos meteorológicos, y una vez dados estos pasos proceder a reflexionar sobre la influencia del factor climático en la vida del hombre (Le Roy Ladurie 1960). Cabe decir que en los mismos años en que Le Roy Ladurie publicó las bases de su obra, 19601962, también apareció en México la traducción al castellano del influyente libro de Françoise Chevalier, La formación de los grandes latifundios en México. Tierra y sociedad en los siglos XVI y XVII, una obra que puso de relieve la trascendencia que había jugado la geografía física y social, así como el devenir climático en la instauración de unidades agrarias, 
la introducción y domesticación de especies animales y vegetales, y el desarrollo de técnicas de trabajo en el virreinato novohispano. Si bien es cierto que el objetivo de Chevalier era vislumbrar la mutación de viejas instituciones hispanas en el mundo americano, también es verdad que aportó reflexiones muy sugerentes sobre la diversidad climática y los estragos que causaban las alteraciones atmosféricas en el mundo agrario. Tal vez el aporte más representativo de esta obra radicó en reconstruir, con fuentes muy heterogéneas, la presencia de fenómenos naturales que impactaron negativamente en las actividades agrícolas y ganaderas de Nueva España. Cabe advertir que su perspectiva del clima se basó en una apreciación cultivada por Paul Vidal de la Blanche y difundida por Fernand Braudel: un componente físico estrechamente asociado a la vida social, y en repetidas ocasiones determinante en el devenir de las civilizaciones (Chevalier 1965).

Una visión panorámica de los trabajos que han coadyuvado al estudio histórico del clima en México pone de relieve que, además del legado francés, otra tradición historiográfica también ha participado en la generación de conocimientos. Me refiero a la geografía cultural impulsada por la Escuela de Berkeley y, especialmente, por Carl O. Sauer, Sherburne F. Cook, Woodrow Borah, Robert C. West, Frances V. Sholes y Ralph L. Roys, quienes, a través de obras con objetivos muy diferentes, pusieron en el centro de sus discusiones el papel que jugó el clima, el paisaje, las enfermedades y la explotación de recursos en la conformación y consolidación de Nueva España (Sauer 1948; Cook 1949; Borah 1951; West 1949; Sholes y Roys 1948). Debo subrayar que en estos trabajos la geografía fue la disciplina que ponderó la influencia del clima en el desarrollo de actividades agrícolas y económicas, así como en la proliferación de enfermedades y en la configuración de desastres; prueba de ello son los trabajos de Sauer, Cook y West para explicar el deterioro ambiental en las provincias de Colima, Teotlalpan y Parral durante los siglos xv y xvi.

Antes de seguir y poner al descubierto la influencia de estos trabajos en los estudios históricos sobre el clima en México, conviene advertir que durante la primera mitad del siglo xx existieron una serie de historiadores que, con una visión documentalista, editaron fuentes sobre el México colonial y republicano; historiadores que sin entrar en discusiones teóricas compilaron materiales muy diversos, entre los cuales aparecen referencias precisas sobre las condiciones climáticas y ambientales del virreinato. Prueba de ello son las colecciones dirigidas por Francisco del Paso y Troncoso, Joaquín García Icazbalceta, Antonio Pompa y Pompa, Miguel Othón de Mendizábal, José Bravo Ugarte y Luis Chávez Orozco. Este último, por cierto, publicó una colección sobre la historia económica de México y veinte tomos sobre la agricultura en Nueva España. En ambos proyectos, las fuentes relacionadas con la producción agraria, el comercio de granos, la colecta de diezmos, el movimientos de precios y las crisis de subsistencia guardaron un vínculo directo e indirecto con la evolución del clima, tal como puede leerse en los volúmenes dedicados a las crisis agrícolas de 1785-1786 y 1908-1909; las compilaciones sobre las alhóndigas de Guadalajara, León, Salamanca y Querétaro; y los textos sobre el cultivo del café y la vid (Chávez Orozco 1953; 1955; 1956).

En este contexto, los estudios históricos con contenido climático fueron cobrando interés entre los historiadores mexicanistas. No obstante, fueron pocos los seguidores y 
aquellos que lo hicieron se distinguieron por enmarcar sus reflexiones bajo los enfoques de la historia económica y la geografía histórica. El resultado fueron trabajos muy heterogéneos y donde el clima fue un elemento secundario en los argumentos explicativos, tal como se evidenció en las obras de Manuel Carrera Stampa sobre la producción y el abasto de granos en el México colonial; el libro de Eduardo Arcila Farías sobre la Nueva España y sus problemas económicos en el campo; los artículos de Rosa Feijóo sobre los tumultos en la Ciudad de México debido a las crisis agrícolas de 1624 y 1692; los análisis de Woodrow Borah sobre la recaudación de diezmos en el obispado de Oaxaca durante los tres siglos de dominación colonial; la historia de Charles Gibson sobre los pueblos del Valle de México y sus múltiples contrariedades en el campo durante los siglos xvi, xvII y xviI; las reflexiones de Enrique Florescano sobre el abasto de granos en las ciudades novohispanas; la investigación de Michael Costeloe sobre los diezmos en el arzobispado de México; y los estudios de Alejandra Moreno Toscano sobre el maíz y las posibilidades geográficas y atmosféricas que ofrecían ciertas provincias del Altiplano Central para su producción en la etapa colonial (Carrera Stampa 1949; Arcila Farías 1955; Feijóo 1964, 1965; Borah 1941, 1949; Gibson 1964; Florescano 1965, 1967; Costeloe 1966; Moreno Toscano 1965).

Cabe subrayar que en 1969 salió a la luz una obra que - desde el punto de vista historiográfico- fue novedosa, influyente y capaz de trazar un sendero donde el clima se posicionó como un elemento central para estudiar la historia agraria, económica y social de México. Me refiero a Precios del maíz y crisis agrícolas en México (1708-1810), un trabajo de Enrique Florescano que inicialmente se presentó como tesis doctoral en la École des Hautes Études en Sciences Sociales y posteriormente se editó como libro en El Colegio de México; una obra inspirada en los Annales e interesada en explicar los grandes problemas de la historia agraria - propiedad, trabajo, producción agrícola, mercado y relaciones ciudad-campo- a partir de las fluctuaciones en los precios del maíz, las coyunturas en los mercados agrarios, la meteorología, las crisis agrícolas y el deterioro que todo esto causaba en la estructura social. En este sentido, el libro de Florescano se distinguió por resaltar la trascendencia de la meteorología en las estructuras de antiguo régimen; estructuras donde la ausencia de lluvias, la presencia de heladas, la impronta de tempestades o la formación de plagas no solo significaban años de malas cosechas sino también períodos prolongados de escasez, acaparamiento, hambre y enfermedad. Lejos ya de los trabajos clásicos sobre el campo novohispano, Precios del maíz planteó un nuevo esquema para investigar, argumentar y hacer historia; una propuesta que, además, analizó procesos y hechos que evidenciaron una historia novohispana acechada por las oscilaciones climáticas (Florescano 1969).

Para entender con mayor precisión lo que significó este libro hay que considerar aquellas obras que siguieron los planteamientos de Florescano. Si bien el interés central de dichos trabajos fue la historia económica y fiscal, lo cierto es que enriquecieron las discusiones de los estudios agrarios y —ante todo- pusieron de relieve el análisis de numerosas fuentes documentales donde el clima y sus manifestaciones físicas eran determinantes para explicar los procesos históricos; prueba de ello son las tesis de grado y —en su momento- los libros de Arístides Medina Rubio, Cecilia Rabell, Rodolfo Pastor, Flor Hurtado, Sil- 
via Galicia y Lidia Espinoza (Hurtado 1974; Medina Rubio 1974, 1984; Rabell 1974, 1986; Pastor 1979, 1987; Galicia 1975; Florescano y Espinoza 1987). Dichos trabajos combinaron de manera rigurosa la historia económica y agraria para reconocer los ciclos agrícolas que eran trastocados por fenómenos climáticos. Sus planteamientos fueron, para la historia novohispana, sumamente novedosos, ya que emplearon fuentes fiscales como indicadores de la producción agraria y de la presencia de oscilaciones atmosféricas. Asimismo, ensayaron algunos modelos para correlacionar las crisis agrícolas y de subsistencia con los brotes epidémicos y los levantamientos sociales, especialmente durante los siglos xviI y xvIII.

En términos generales, puede decirse que los trabajos de Florescano y sus alumnos fueron muy relevantes, y si no tuvieron un mayor número de seguidores en su momento fue porque, en el contexto nacional, la historia económica se apoderó de los espacios de discusión y cegó muchas posibilidades para analizar los procesos históricos. No obstante, sus contribuciones fueron reconocidas - durante los años setenta y ochenta-como una forma nueva para investigar y escribir la historia, y -sobre todo- para plantear interrogantes que ayudaron a comprender los cambios profundos del campo a partir de fenómenos climáticos globales y - por ende- manifestaciones locales. También habrá que subrayar que estos trabajos fueron muy explícitos al referir que sus aportaciones eran un puente para acercarse a las ideas y los métodos pregonados por una serie de autores franceses - como Ernest Labrousse, Pierre Goubert, Jean Meuvret y Emmanuel Le Roy Ladurie- que vislumbraban en la historia serial y climática una alternativa para entender la Edad Moderna.

Durante la década de los setenta también aparecieron estudios donde la evolución histórica del clima fue referida como un componente en la configuración de espacios sociales, regiones económicas y zonas de producción; estudios que, en su mayoría, encontraron en la geografía francesa y norteamericana una serie de herramientas para el desarrollo de sus argumentos. Dado lo anterior, no es casualidad que en dichos trabajos el clima se planteara como un componente de la geografía física y casi siempre bajo una perspectiva que carecía de profundidad histórica; prueba de ello son los trabajos de Elinore Barret sobre la cuenca del Tepalcatepec, Richard Boyer sobre la Ciudad de México en el siglo xvir, Claude Morin sobre el obispado de Michoacán en el siglo xviI, David Brading sobre los enclaves mineros y agrícolas del Bajío novohispano, y Eric Van Young sobre las haciendas y la producción agraria en la Nueva Galicia (Barret 1975; West 1976; Boyer 1975; Morin 1979; Brading 1971; Van Young 1981).

Hacia finales de los años setenta, salvo la obra de Florescano y sus alumnos, el clima era considerado en los estudios históricos de México como un componente del entorno, con poco dinamismo histórico y con bases interpretativas en la geografía física.

\section{Un horizonte para muchas historias}

Situando este balance historiográfico en las décadas de los años ochenta y noventa, saltan a la vista una serie de hechos que bien pueden considerarse como formas nuevas para 
abordar el clima en los estudios históricos. Debo precisar que dichas formas se manifestaron en tres propuestas analíticas. La primera de ellas se integró por un conjunto de trabajos que, con un interés muy claro en la historia agraria y regional, se dieron a la tarea de reconstruir una serie de procesos del México colonial donde el clima, la geografía física, el componente humano y las actividades agrarias estaban estrechamente articulados. Por algunos momentos, estos trabajos pisaron el terreno de la historia del clima al tratar de reconstruir las condiciones atmosféricas y ambientales que habían provocado una serie de sequías, inundaciones, heladas, plagas y migraciones durante los siglos xvII y xviII; asimismo, procuraron mostrar los efectos de estos fenómenos naturales al tiempo de impactar en las estructuras económicas y sociales de algunas regiones, tal como lo evidenciaron los trabajos de Rodolfo Pastor para la Mixteca oaxaqueña, Arij Ouweneel para el Altiplano Central de México, Daniele Dehouve en la montaña de Guerrero, Nancy Farriss en la península de Yucatán, James Lockhart en los pueblos nahuas del México central, Wolfgang Trautmann en el paisaje físico de Tlaxcala, Teresa Rojas Rabiela en el devenir de la agricultura en México, así como Juan Carlos Garavaglia y Juan Carlos Grosso en los valles agrícolas y ganaderos de Puebla; estudios que, en términos generales, combinaron nociones básicas de la climatología histórica con un esfuerzo sistemático para evidenciar las características del entorno físico y los riesgos naturales en que vivían las poblaciones nativas del período colonial (Pastor 1987; Ouweneel 1996; Dehouve 1990; Farriss 1992; Lockhart 1992; Trautmann 1981; Rojas Rabiela 1983; Garavaglia y Grosso 1994). Sus planteamientos para la historiografía mexicana fueron sumamente novedosos, pues revelaron enfoques analíticos y fuentes de información muy diversos para estudiar las crisis en el campo y en las ciudades. No obstante, una de sus principales contribuciones radicó en evidenciar que, a lo largo de los siglos xVII y xviII, ocurrieron numerosos eventos de clima extremo y que buena parte de ellos contribuyeron a la formación de hambrunas, brotes epidémicos, crisis de subsistencia y revueltas sociales.

La segunda propuesta se integró por una serie de estudios orientados a documentar y reflexionar la presencia de fenómenos naturales extremos en la historia de México. Cabe decir que buena parte de estos trabajos centraron su atención en fenómenos que eran resultado de alteraciones climáticas, tal como ocurrió con los estudios dedicados a las sequías. Al respecto, Enrique Florescano volvió a figurar como uno de los precursores de esta línea de trabajo, pues entre 1980 y 1995 sacó a la luz una serie de textos e inspiró otros tantos que se encargaron de explicar los orígenes, los procesos evolutivos y los efectos de las sequías. Un rasgo distintivo de dichos trabajos es que proporcionaron una visión panorámica de este fenómeno - desde tiempos precolombinos hasta bien entrado el siglo xx-, ponderaron las áreas geográficas de mayor afectación y revelaron la manera en que una serie de componentes geográficos y sociales agravaban los efectos de las sequías. En general, dichos textos se distinguieron por emplear conceptos y herramientas propios de la climatología histórica, así como contextos emanados de la historiografía del clima. Si bien es cierto que fueron considerados como trabajos novedosos y propositivos, también es verdad que definieron un plano historiográfico donde la sequía -como manifestación climática-se posicionó como eje central en la explicación de ciertos procesos; inclusive, es- 
tas obras afianzaron una perspectiva analítica donde el objeto de estudio eran las condiciones atmosféricas y sus manifestaciones físicas. La propuesta fue tan bien recibida que dichos trabajos tuvieron la capacidad de incidir en una serie de instituciones académicas y dependencias gubernamentales que no dudaron en patrocinar investigaciones para entender las sequías de los siglos xIx y xx (Florescano et al. 1980; Florecano y Pastor 1981; Florescano y San Vicente 1985; Florescano y Swan 1995).

Como era de esperar, las propuestas de Florescano no solo fueron bien recibidas en el medio académico, sino que también alentaron una serie de investigaciones que se distinguieron por enlazar las sequías con las crisis agrícolas acaecidas en los siglos xIx y xx, emplear conceptos y argumentos propios de la meteorología, y tomar desde luego perspectivas analíticas derivadas de la historia y geografía. Prueba de ello son las investigaciones de Enriqueta García sobre las anomalías climáticas del siglo xx, Virginia García Acosta sobre las sequías registradas en la historia de México, Antonio Escobar Ohmstede sobre las sequías en la Huasteca del siglo xix, Pedro Bracamontes sobre la escasez de humedad en la península de Yucatán, Luis Aboites y Gloria Camacho sobre las sequías en el occidente de México, así como Sarah L. O'Hara y Sara E. Metcalfe sobre las sequías y sus vínculos con las pulsaciones climáticas de los últimos cuatrocientos años (Aboites y Camacho 1996; Bracamonte 1998; Escobar 1992, 1997; García 1988, 1996; García Acosta 1993; O’Hara y Metcalfe 1994, 1995).

La tercera propuesta se conformó por un grupo de historiadores y antropólogos reunidos en torno a Virginia García Acosta. Todos o casi todos se distinguieron por reconocer las complejidades del mundo natural, en general, y del clima, en particular, así como su influjo en las estructuras sociales, económicas y políticas. Entre 1995 y 2010 publicaron una serie de estudios que enlazaban los fenómenos climáticos extremos y las respuestas sociales e institucionales ante dichas amenazas; también publicaron una serie de reflexiones sobre la naturaleza extrema y los procesos de vulnerabilidad social. ${ }^{2} \mathrm{Al}$ paso del tiempo, el grupo encabezado por García Acosta se constituyó como un equipo pluridisciplinario y especializado en el estudio histórico de los desastres. Lo más significativo de este grupo radica en que, además de abrir numerosos horizontes analíticos y discusiones conceptuales, se dio a la tarea de publicar un enorme cúmulo de información donde el clima y sus manifestaciones eran una constante en la historia de México; una constante que al examinarse con enfoques propios de la climatología saltaban a la vista secuencias, períodos, ciclos y hechos que revelaban procesos complejos en la atmósfera y que se traducían en sequías, lluvias torrenciales, tormentas, heladas, nevadas, huracanes, tempestades, ciclones, plagas, etcétera. Es de advertir que buena parte de este grupo se interesó, entre otras cosas, por el análisis histórico de los desastres, así como por dilucidar y explicitar cuáles eran los factores que los configuraban y potenciaban en el tiempo, implicando de paso una revisión crítica y novedosa a las historias regionales e institucionales que, a dife-

2. Entre los antropólogos e historiadores que trabajaron en estos proyectos con Virginia García Acosta, sobresalieron: Luis Aboites Aguilar, América Molina del Villar, Antonio Escobar Ohmstede, Rocío Hernández, Irene Márquez, Juan Manuel Pérez Zevallos, Juan Pedro Viqueira, entre otros. 
rencia de otras propuestas, trataban con poco rigor las manifestaciones extremas de la naturaleza. Por si esto no fuera suficiente, otro de los grandes aportes de este grupo radicó en construir puentes de diálogo y colaboración con climatólogos, biólogos, entomólogos, físicos, sismólogos, etcétera; puentes que dieron como resultado trabajos muy novedosos sobre los denominados «desastres agrícolas», las «calamidades en el campo» y los «años estériles» (García Acosta 2003). Una aportación más que debe destacarse en este grupo de trabajo es que enriquecieron las discusiones historiográficas, impulsaron la edición de compilaciones documentales y - sobre todo- proveyeron numerosos recursos para que la climatología y meteorología histórica proyectaran sus análisis en el tiempo.

Situándose a principios del siglo xxi y haciendo un balance de los estudios históricos del clima, puede decirse que para estas fechas ya se contaba con dos planos historiográficos plenamente reconocidos: uno, conformado por trabajos que proponían el estudio y la interpretación de los fenómenos climáticos a partir de la historia agraria, la historia económica y los estudios históricos de los desastres; dos, las obras que desde la historia y la geografía pusieron en práctica métodos y enfoques propios de la climatología y meteorología para explicar una serie de fenómenos naturales. Con ambos se analizaron aspectos nunca antes tratados durante los siglos xvII, XviI y XIX, y sobre todo se descubrieron una serie de fuentes documentales para entender el devenir climático; tal es el caso de las rogativas, plegarias, sermones, procesiones, exvotos, registros de nieve y sal, construcción de obras públicas, etcétera.

\section{Los desafíos y la especialización del presente}

Junto a la publicación de fuentes de origen físico-biológico y antrópico sobre el clima en México, los estudios de los últimos veinte años se han caracterizado por tener un acercamiento crítico a la variabilidad atmosférica, tanto en períodos geológicos como en etapas históricas (Garza Merodio 2017). Sin duda, los estudios encargados de las etapas geológicas son los que han puesto de relieve la necesidad de emplear la tecnología e interdisciplinariedad para conocer los niveles de precipitación que han determinado la variabilidad climática en el tiempo. De ahí la importancia de los trabajos realizados con el apoyo de la dendrocronología, glaciología, geología, el análisis de suelos y sedimentos, y el estudio de polen y fósiles animales, para determinar las condiciones climáticas y ambientales en escenarios remotos en el tiempo —entre cinco mil y diecisiete mil años-. Por cierto, en estos estudios se han generado conocimientos trascendentes para el centro y occidente de México, la península de Yucatán y las planicies costeras del Golfo; estudios que han mostrado la forma en que las oscilaciones del clima inciden en las comunidades vegetales - terrestres y acuáticas-, producen períodos prolongados de humedad y sequía, trastornan los ecosistemas y - ante todo- provocan procesos de interacción con el hombre, ya sea para adaptarse, resistir o modificar las condiciones ambientales impuestas (Torres Rodríguez et al. 2012; Hodell et al. 2007; Magaña et al. 1999; Therrell et al. 2006; Stahle et al. 2011; Hunt y Elliot 2002; Folan 1983). Es importante remarcar que estos estudios tienen 
como fundamento la información generada por instrumentos y por modelos matemáticos que recrean las condiciones atmosféricas del pasado. Si bien estos trabajos son muy sugerentes y propositivos en la generación de conocimientos, lo cierto es que muchas investigaciones históricas los pasan por alto y no los consideran como elementos centrales para reconstruir contextos y procesos climáticos en el tiempo.

Una excepción al respecto son las investigaciones que, en últimas décadas, se circunscriben como parte de la denominada climatología histórica; es decir, investigaciones donde el objeto de estudio son los fenómenos atmosféricos que se han presentado en las denominadas etapas históricas, que contemplan todas sus complejidades y escalas (temporales y espaciales) y que suelen examinarse a partir de información documental e instrumental. Inclusive, puede decirse que estos trabajos evocan el camino hacia una línea para investigar fenómenos y períodos que habían estado desatendidos. En este orden, dichas investigaciones resultan novedosas no solo por sus enfoques, sino también por los argumentos explicativos, tal como ocurre con los trabajos realizados por Gustavo Garza Merodio para el período colonial. Es de advertir que sus pesquisas abrieron nuevos derroteros para la climatología histórica en México, sirviéndose de documentos poco consultados y de argumentos que combinan el análisis histórico y climatológico. Para ello, se dio a la tarea de sistematizar información de cabildos civiles y eclesiásticos sobre rogativas, procesiones, misas, sermones y obvenciones, tras cuyo análisis aparecieron evidencias notables para la historia del clima y para el entendimiento de los efectos que ciertos fenómenos causaban en el campo, en las ciudades y en la población. Con esto, se hizo evidente que la climatología histórica tenía una fuente de información muy abundante y que, aun siendo conocida, conservaba datos relevantes para construir nuevas interpretaciones históricas. Inclusive, Garza Merodio hizo otra aportación al subrayar la trascendencia de los contextos climáticos para entender y vislumbrar la riqueza de los documentos históricos; de ahí su énfasis en estudiar los fenómenos acaecidos durante la PEH (Garza Merodio 2002, 2006, 2017).

Casi simultáneamente, con la aparición de estos trabajos también salieron a la luz una serie de investigaciones que combinaron la climatología histórica con los argumentos de la historia ambiental; estudios que no solo abordaron problemas de exceso o carencia de humedad, sino también reconstruyeron series de temperaturas; inclusive, algunos revelaron la manera en que ciertas prácticas forestales, hidráulicas, ganaderas y agrícolas habían agudizado los efectos del clima extremo. Una muestra de ello son los trabajos de Georgina Endfield sobre las inundaciones y sequías en el centro y sur de México durante el siglo xviII. Dicha autora revisó críticamente los estudios realizados en México durante los últimos cuarenta años y evidenció cuánto se había avanzado al respecto. Con un método riguroso y con lecturas provenientes de la historia ambiental, Endfield analizó una serie de documentos civiles para desentrañar información de orden climático que otros no habían advertido (Endfield 1997, 2007; Endfield y O'Hara 1999, 2004). Algo muy semejante se desprende de los trabajos de Alejandro tortolero Villaseñor, quien ha centrado la atención en la tecnificación del campo mexicano y - por ende-en los procesos de deterioro y transformación ambiental; factores que al analizarse en las fuentes de los siglos xvII, xIx y xx permiten distinguir una serie de anomalías climáticas que impactaron en diversas porcio- 
nes de la geografía mexicana (Tortolero 2008). Debe subrayarse que esta lectura minuciosa de fuentes es una de las herramientas más distintivas que ha proveído la climatología para conformar bancos de información y advertir un principio básico en los estudios del clima: todas las manifestaciones atmosféricas, a cualquier escala que se consideren -minutos, horas, días, semanas, meses, años y siglos- están fluctuando y comportándose de manera imprevista; de ahí la necesidad de evidenciarlas y estudiarlas (Garza Merodio 2017; Nash et al. 2021).

Quien esto escribe también encontró en el legado historiográfico referido un campo de oportunidades para adentrarse en el devenir del clima y en las complejidades de la climatología histórica. De hecho, procuré tener presente todo este legado historiográfico para examinar con rigor una de las consecuencias más evidentes de la variabilidad climática: la formación de plagas de langosta en el sudeste de México durante los siglos XviI y XIX (Arrioja 2012). También retomé la bibliografía referida para editar con Armando Alberola Romá una obra colectiva intitulada Clima, desastres y convulsiones sociales en España e Hispanoamérica, siglos XVII-XX, y con ello impulsar otro enfoque para analizar el devenir climático en México: «la larga historia del clima, es decir, esa historia donde individuos y sociedades interactúan con realidades propias de la meteorología y con horizontes donde el clima evoluciona e impone condiciones, y donde los humanos sortean su condición vulnerable, soportando exigencias ambientales y desplegando estrategias para adaptarse al medio» (Arrioja y Alberola 2016). Así, al colocar el clima en el centro del análisis fue posible ver de qué manera las grandes pulsaciones térmicas de la $\mathrm{PEH}$ se manifestaron en diversas regiones de México y —-sobre todo-gestaron una serie de historias seculares de gran relevancia. Para lograrlo fue importante emplear conjuntamente las propuestas de la climatología histórica, la información recopilada por los estudios históricos de desastres y los argumentos proveídos por la historiografía del clima. De hecho, con el enfoque propuesto en este libro ha sido posible emprender estudios similares en otras áreas geográficas y períodos cronológicos, como en Ciudad de México, Colima, Oaxaca, Puebla, Veracruz y Chiapas (Ramírez Vega 2021; García Ruiz 2016; García Torres 2017; Padilla Lozoya 2016; Campos Goenaga 2011). Además, quien esto escribe ha desarrollado otros estudios que tienen como eje central la historia del clima durante los siglos XviI y xIx pero circunscrita a fenómenos y eventos que han impactado tanto en el territorio mexicano como centroamericano (Arrioja 2019, 2017, 2015).

Así las cosas, puede decirse que — hacia la segunda década del siglo xxi— los estudios históricos del clima en México son una realidad y encuentran su desarrollo en tres campos del conocimiento: la historia del clima, la climatología histórica y los estudios históricos de los desastres. Vale anotar que en dichos campos se han percibido aspectos nunca antes tratados en la historia colonial y republicana, y se han detectado la presencia de pulsaciones atmosféricas circunscritas en la etapa final de la $\mathrm{PEH}$, especialmente en el período 17501860. Por si esto no fuera suficiente, se ha avanzado con creces en el diálogo con otras disciplinas de las ciencias sociales y - sobre todo- se han construido puentes comunicantes con las ciencias biológicas, físicas y ambientales; puentes que han coadyuvado en la generación de conocimientos y en la mejor comprensión del devenir climático en México. 


\section{Comentarios finales}

A lo largo de estas páginas he revisado y examinado una serie de estudios históricos que han centrado su atención en el clima, en sus manifestaciones físicas y en los efectos que dichas manifestaciones han causado en las estructuras sociales, económicas y agrarias del México colonial y republicano. En este orden, he planteado que dicha revisión permite vislumbrar los alcances y los límites historiográficos en las últimas cinco décadas. En cuanto a los alcances, salta a la vista que estos estudios han avanzado notablemente en perspectiva y profundidad analítica, en diversidad temática y espacial, en argumentación conceptual y en el uso de métodos, así como en la construcción de diálogos interdisciplinarios. Los pocos pero valiosos trabajos de climatología histórica son dignos de atenderse y seguirse en los años venideros. También son evidentes los avances que se han tenido en los estudios de las sequías y las crisis agrícolas de la etapa colonial; asimismo, los impulsos dados a la publicación de fuentes y bancos de información, así como al estudio de documentos civiles y religiosos que resguardan contenidos notables sobre el devenir climático.

En lo que respecta a las limitaciones historiográficas, debo advertir que buena parte de los estudios han concentrado su atención en los siglos xvi y xviII, con lo cual se tiene un conocimiento muy limitado del siglo xvı y - por ende- de los siglos xix y xx. Si bien las explicaciones vertidas para lo acaecido en el siglo xvi estriban en la carencia de información, lo cierto es que para los siglos xix y xx se plantea un desinterés académico, pues como se sabe son períodos que disponen de grandes volúmenes de documentos seriados, instituciones encargadas de registrar y vigilar las condiciones climáticas, y -sobre todo- manifestaciones climáticas que se evidenciaron a lo largo y ancho del país. En estrecha relación con lo anterior, puede decirse que se ha hecho muy poco en cuanto a la proyección de estudios históricos del clima en los siglos xix y xx. Es decir, no se ha conformado un grupo de trabajo que con preocupaciones y problemas puntuales se dedique exclusivamente a examinar los fenómenos atmosféricos extremos y sus implicaciones en la vida nacional. Tal vez la excepción se encuentra entre los antropólogos y geógrafos interesados en rastrear los procesos de vulnerabilidad y la configuración de desastres en el siglo xx, así como en los climatólogos dedicados a estudiar el fenómeno denominado El Niño Southern Oscilation (ENSO) y la cadena de huracanes y tormentas que han afectado el país en los últimos veinte años. No obstante, habrá que decir que son obras cuyos objetivos e intereses se encuentran muy distantes del análisis histórico del clima. A lo anterior se suma una concentración de investigaciones en fenómenos relacionados con la escasez y abundancia de humedad; sin embargo, siguen faltando reflexiones que atiendan otros fenómenos que están presentes en la historia de México y que se han manifestado en forma de heladas, huracanes, tempestades, nevadas, plagas biológicas, introducción de especies animales y vegetales, aparición y mutación de enfermedades, y un largo etcétera. Sobre estas posibilidades futuras, tengo conocimiento que en fechas recientes aparecerá un catálogo histórico sobre huracanes en la historia de México bajo la dirección de Virginia García Acosta y Raymundo Padilla, así como un par de volúmenes intitulados Estudios de historia y clima, bajo la coordinación de quien suscribe y Armando Alberola Romá, que tienen la intención 
de analizar las diferentes pulsaciones climáticas acaecidas durante la etapa final de la PEH y sus múltiples implicaciones en América y España. En paralelo, se suman una serie de tesis que actualmente se prepararan en El Colegio de Michoacán, El Colegio de México, el Centro de Investigaciones en Estudios Superiores en Antropología Social, la Universidad de Colima y Universidad de Ciencias y Artes de Chiapas, donde el clima y su intervención en los procesos históricos son una realidad. Sirva este balance para ponderar lo que se ha realizado en los estudios históricos del clima en las últimas décadas y para vislumbrar los derroteros que seguir en el corto y medio plazo.

\section{Bibliografía}

Aboites, L.; Camacho, G. (1996). «Aproximación al estudio de una sequía en México: el caso de Chapala-Guadalajara (1949-1958)». En V. GarCía Acosta (coord.). Historia y desastres en América Latina. Vol. 1. México: LA RED / Centro de Investigaciones y Estudios Superiores en Antropología Social.

ARCILA FARÍAs, E. (1955). El siglo ilustrado en América. Reformas económicas en Nueva España. Caracas: Ediciones del Ministerio de Educación.

Arrioja, L. A. (2012). «Enjambres y nubarrones en el campo oaxaqueño: las plagas de langosta de 1802 y 1853», Relaciones. Estudios de historia y sociedad, núm. 129, pp. 161213.

ARrioja, L. A. (2013). «Guatemala y Nueva España: historia de una plaga compartida, 17981807», Revista de Historia Moderna. Anales de la Universidad de Alicante, núm. 33, pp. $1-15$.

Arrioja, L. A. (2015). «Entre el resplandor de las luces y las amenazas de insectos. Comentarios a la Instrucción sobre la plaga de langosta dispuesta por el Superior Gobierno de Guatemala en 1804». En A. Alberola Romá. Riesgo, desastre y miedo en la península Ibérica y México durante la Edad Moderna. Alicante: Universidad de Alicante / El Colegio de Michoacán, pp. 253-284.

Arrioja, L. A. (2019). Bajo el crepúsculo de los insectos. Clima, plagas y trastornos sociales en el reino de Guatemala (1768-1805). México: El Colegio de Michoacán / Universidad de San Carlos de Guatemala / FLACSO / Universidad Nacional Autónoma de Honduras.

Arrioja, L. A.; Alberola, A. (eds.) (2016). Clima, desastres y convulsiones sociales en España e Hispanoamérica, siglos XVII-XX. México: El Colegio de Michoacán / Universidad de Alicante.

BARRET, E. (1975). La cuenca del Tepalcatepec. 2 vols. México: Secretaría de Educación Pública.

Borah, W. (1941). «The Collection of Tithes in the Bisopric of Oaxaca during the Sixteenth Century», Hispanic American Historical Review, vol. 21, pp. 386-409.

Borah, W. (1949). «Tithe Collection in the Bisopric of Oaxaca: 1601-1867», Hispanic American Historical Review, vol. 29, pp. 498-517. 
Borah, W. (1951). New Spain's Century of Depression. Berkeley: University of California Press. Boyer, R. (1980). La gran inundación. Vida y sociedad en México, 1629-1638. México: Secretaría de Educación Pública.

Bracamonte, P. (1998). «Los mayas de la montaña: la conquista inconclusa» (Tesis doctoral). México: Universidad Nacional Autónoma de México.

BRAding, D. (1971). Miners and Merchants in Bourbon Mexico, 1763-1810. Cambridge: Cambridge University Press.

Campos Goenaga, I. (2011). Entre crisis de subsistencia y crisis colonial. La sociedad yucateca y los desastres en la coyuntura 1765-1774. México: Escuela Nacional de Antropología e Historia / Instituto Nacional de Antropología e Historia / Consejo Nacional para la Cultura y las Artes.

Carrera Stampa, M. (1949). «The Evolution of Weights and Measures in New Spain», Hispanic American Historical Review, vol. 29, pp. 2-24.

Contreras Servín, C. (1999). «El clima de la república mexicana en el siglo xix» (Tesis doctoral). México: Universidad Nacional Autónoma de México.

Cook, S. F. (1949a). Soil Erosion and Population in Central Mexico. Berkeley: University of California Press.

Cоoк, S. F. (1949b). The Historical Demography and Ecology of the Teotlalpan. Berkeley: University of California Press.

Costeloe, M. (1966). «The Administration, Collection and Distribution of Tithes in the Arch Bishopric of Mexico, 1800-1860», The Americas, vol. 23, pp. 1-27.

Chávez Orozco, L. (1953). La crisis agrícola novohispana de 1784-1785. México: Publicaciones del Banco Nacional de Crédito Agrícola y Ganadero.

Cook, S. F. (1955). Documentos sobre la albóndiga de Querétaro. México: Almacenes Nacionales de Depósito.

Coor, S. F. (1956a). Documentos sobre la albóndiga de las villas de León y Salamanca en la intendencia de Guanajuato. México: Almacenes Nacionales de Depósito.

Соок, S. F. (1956b). Más datos para la bistoria de la albóndiga de Guanajuato. México: Almacenes Nacionales de Depósito.

Chevalier, F. (1965). La formación de los latifundios en México. Tierra y sociedad en los siglos xVI y XVII. México: Fondo de Cultura Económica.

Dehouve, D. (1990). Quand les banquiers étaient des saints: 450 ans de l'bistoire economique et sociale d'une province indienne du Mexique. París: Centre National de la Recheche Scientifique.

Domínguez Castro, F. et al. (2019). "Twelve years of daily weather descriptions in North America in the eighteenth century (Mexico City, 1775-86)», Bulletin of the American Meteorological Society, vol. 100, pp. 1531-1547.

Endfield, G. (1997). «Social and Environmental Change in Colonial Michoacán, West Central Mexico» (Tesis doctoral). Sheffield: University of Sheffield.

Endfield, G. (2004). «Drought and Disputes, Deluge and Dearth: Climatic Variability and Human response in Colonial Oaxaca, Mexico», Journal of Historical Geography, vol. 30, pp. 249-276. 
Endfield, G. (2007). «Archival Explorations of Climate Variability and Social Vulnerability in Colonial Mexico», Climatic Change, vol. 83, pp. 9-38.

Endfield, G.; O'HARA, S. (1997). «Conflicts over Water in The Little Drought Age in Central Mexico», Environment and History, vol. 3, pp. 255-272.

Endfield, G.; O'HaRA, S. (1999). «Degradation, Drought, and Dissent: An Environmental History of Colonial Michoacán, West Central Mexico», Annals of the Association of American Geographers, vol. 89, pp. 402-419.

Escobar Ohmstede, A. (1992). «Desastres naturales del siglo xix: avances de una investigación». En V. García Acosta (coord.). Estudios Históricos sobre desastres naturales en México. México: Centro de Investigaciones y Estudios Superiores en Antropología Social.

Escobar Ohmstede, A. (1997). «Las sequías y sus impactos en las sociedades del México decimonónico, 1856-1900». En V. García Acosta (coord.). Historia y desastres en América Latina. Lima: LA RED / Centro de Investigaciones y Estudios Superiores en Antropología Social / ITDG.

Fagan, B. (2008). La pequeña edad de hielo. Cómo el clima afectó a la bistoria de Europa, 1300-1850. Barcelona: Editorial Gedisa.

FARRISS, N. (1992). Maya Society Under Colonial Rule: the Collective Enterprise of Survival. Princeton: Princeton University Press.

Feijóo, R. (1964). «El tumulto de 1624», Historia Mexicana, vol. 14, pp. 42-70.

Feijóo, R. (1965). «El tumulto de 1692», Historia Mexicana, vol. 14, pp. 656-679.

Florescano, E. (1965). «El abasto y la legislación de granos en el siglo xvI», Historia Mexicana, vol. 14, pp. 567-630.

FloresCANo, E. (1967). «Notas sobre la producción histórica en México», La Palabra y el Hombre, pp. 525-547.

Florescano, E. (1969). Precios del maíz y crisis agrícolas en México (1708-1810). Ensayo sobre el movimiento de los precios y sus consecuencias económicas y sociales. México: El Colegio de México.

Florescano, E. et al. (1980). «Las sequías en México: historia, características y efectos», Comercio Exterior, vol. 30, pp. 747-757.

Florescano, E.; Espinoza, L. (1987). Fuentes para el estudio de la agricultura colonial en la diócesis de Michoacán. Serie de Diezmos, 1636-1810. México: Instituto Nacional de Antropología e Historia.

Florescano, E.; PAStor, R. (1981). Fuentes para la historia de la crisis agrícola de 1785-1786. 2 vols. México: Archivo General de la Nación.

Florescano, E.; SAn Vicente, V. (1985). Fuentes para la bistoria de la crisis agrícola de 1809-1810. 2 vols. México: Archivo General de la Nación.

Florescano, E.; Swan, S. (1995). Breve historia de la sequía en México. Xalapa: Universidad Veracruzana.

Folan, W. J. et al. (1983). «Paleoclimatological Patterning in Southern Mesoamerica», Journal of Field Archaeology, vol. 10, pp. 453-468.

Galicia, S. (1975). Precios y producción en San Miguel el Grande, 1661-1803. México: Instituto Nacional de Antropología e Historia. 
Garavaglia, J. C.; Grosso, J. C. (1994). Puebla desde una perspectiva microbistórica: la villa de Tepeaca y su entorno agrario: población, producción e intercambio, 1740-1870. México: Claves Latinoamericanas.

García, E. (1988). «Anomalía de la precipitación en la república mexicana de 1921 a 1980», Revista de Geografía, núm. 2, pp. 1-24.

García, E. (1996). «Evaluación de la sequía intraestival en la república mexicana», Unión Geográfica Internacional. Tomo 3, México: Sociedad Mexicana de Geografía y Estadística.

García Acosta, V. (1993). «Las sequías históricas en México», Desastre y sociedad, núm. 1, pp. 83-97.

García Acosta, V. et al. (2003). Desastres agrícolas en México. Catálogo histórico. Tomo I. Época prehispánica y colonial (958-1822). México: Fondo de Cultura Económica / Centro de Investigaciones y Estudios Superiores en Antropología Social.

García Ruiz, L. J. (2016). «Ciclones tropicales: su impacto social y económico en las poblaciones del Golfo de México. Siglos xviI-XIX». En L. A. Arrioja y A. Alberola (eds.). Clima, catástrofes y convulsiones sociales en España e Hispanoamérica, siglos XVII-XX. México: El Colegio de Michoacán / Universidad de Alicante, pp. 225-242.

García Torres, A. (2017). «La religiosidad popular frente a la sequía en la ciudad de México (1700-1760)», Temas Americanistas, núm. 38, pp. 32-56.

Garza Merodio, G. (2002). «Frecuencia y duración de sequías en la cuenca de México de fines del siglo xvi a mediados del XIX», Investigaciones Geográficas, núm. 48, pp. 106115.

Garza Merodio, G. (2006). «Climatología histórica: las ciudades mexicanas ante la sequía (Siglos xvI al xix)», Investigaciones Geográficas, núm. 63, pp. 77-92.

Garza Merodio, G. (2017). Variabilidad climática en México a través de fuentes documentales (siglos XVI al XIX). México: Universidad Nacional Autónoma de México.

Gibson, C. (1964). The Aztec Under the Spanish Rule. A History of the Indians of the Valley of Mexico, 1519-1810. Stanford: Stanford University Press.

Hodell, D. A. et al. (2007). «Climate and Cultural History of the Northeastern Yucatan Peninsula, Quintana Roo, Mexico», Climate Change, núm. 83, pp. 215-240.

Hunt, R. G.; Elliot, T. I. (2002). «Mexican Megadrought», Climate Dynamics, vol. 20, pp. 1-12.

HurTado, F. (1974). «Dolores Hidalgo. Estudio histórico económico, 1740-1790» (Tesis de licenciatura). México: Universidad Nacional Autónoma de México, p. 128.

HurTado, F. (1978). «Dolores Hidalgo en el siglo xviI: una aproximación cuantitativa», Historia Mexicana, vol. 27, pp. 507-541.

Le Roy Ladurie, E. (1960). «Climat et récoltes: Aux xvite et xviıe Siècles». Annales. Histoire, Sciences Sociales, núm. 3, pp. 434-465.

Le Roy Ladurie, E. (1961). «Aspects historiques de la nouvelle climatologie». Revue Historique, núm. 225, pp. 1-20.

Le Roy Ladurie, E. (1963). «La conférence d'Aspen su le climat des xie et xvie siècles". Annales. Histoire, Sciences Sociales, núm. 4, pp. 764-766. 
Le Roy Ladurie, E. (1965). «Le climat des xie et xvie siècles: Séries comparées». Annales. Histoire, Sciences Sociales, núm. 5, pp. 899-922.

Le Roy Ladurie, E. (1967). Histoire du climat depuis l'an mil. 2 vols. París: Flamarion.

Lockнавт, J. (1992). The Nabuas After the Conquest. A Social and Cultural History of the Indians of Central Mexico, Sixteenth through Eighteenth Centuries. Stanford: Stanford University Press.

Magaña, V. et al. (1999). «The Midsummer Drought over Mexico and Central America», Journal of Climate of American Meteorological Society, vol. 12, pp. 1577-1588.

Medina Rubio, A. (1974). «Elementos para una economía agrícola: Puebla» (Tesis doctoral). México: El Colegio de México.

Medina Rubio, A. (1984). La iglesia y la producción agrícola en Puebla, 1540-1795. México: El Colegio de México.

Moreno Toscano, A. (1965). «Tres problemas de la geografía del maíz, 1600-1624», Historia Mexicana, vol. 14, pp. 631-655.

Morin, C. (1979). Michoacán en la Nueva España del siglo xVII: crecimiento y desigualdad en una economía colonial. México: Fondo de Cultura Económica.

NASH, D. et al. (2021). «Climate Indices in Historical Climate Reconstructions: A Global State of the Art», Climate of the Past, vol. 17, pp. 1273-1314.

O'hara, S.; Metcalfe, S. (1994). «On the Arid Margin: The Relationship Between Climate Humans and Environment. A Review of Evidence from Highlands of Central Mexico», Chemosphere, núm. 29, pp. 965-981.

O'hara, S.; Metcalfe, S. (1995). «Reconstructing the Climate of Mexico from Historical Records», The Holocene, núm. 5, pp. 485-490.

OuwEneEl, A. (1996). Shadows over Anabuac: An Ecological Interpretation of Crisis and Development in central Mexico, 1730-1800. Albuquerque: University of New Mexico Press.

Padilla Lozoya, R. (2016). «El surgimiento de una sociedad vulnerable y sus respuestas ante amenazas naturales: San José del Cabo, Baja California Sur». En L. A. Arrioja y A. AlbeROLA (eds.). Clima, catástrofes y convulsiones sociales en España e Hispanoamérica, siglos XVII-Xx. México: El Colegio de Michoacán / Universidad de Alicante, pp. 243-268.

PAstor, R. (1981). «Campesinos y reformas. La Mixteca, 1740-1856» (Tesis doctoral), México: El Colegio de México.

Pastor, R. (1987). Campesinos y reformas. La Mixteca, 1700-1856. México: El Colegio de México.

PRIETO, M. del R. et al. (2018). «La climatología histórica en Latinoamérica. Desafíos y perspectivas», Bulletin de I'Institut Français d'Etudes Andines, núm. 47/2, pp. 141-167. Rabell, C. (1974). «San Luis de la Paz: estudio de economía y demografía históricas (16451810)» (Tesis de licenciatura). México: Escuela Nacional de Antropología e Historia.

Rabell, C. (1986). Los diezmos de San Luis de la Paz. Economía en una región del Bajío en el siglo XVIII. México: Universidad Nacional Autónoma de México.

Ramírez Vega, M. D. (2021). «Sequías, plagas de langosta y crisis agrícola en el virreinato de Nueva España, 1765-1780» (Tesis doctoral). México: El Colegio de Michoacán. 
Rojas RABiela, T. (comp.) (1983). La agricultura chinampera: compilación histórica. México: Universidad Autónoma de Chapingo.

Sauer, C. O. (1948). Colima of New Spain in the Sixteenth Century. Berkeley: University of California Press.

Sholes, F.; Roys, R. (1948). The Maya Chontal Indians of Acalan-Tixchel. A Contribution to the History and Ethnography of the Yucatan Peninsula. Washington: Carnegie Institution.

Stahle, D. W. et al. (2011). «Major Mesoamerican Drougts of the Past Millennium», Geophysical Research Letters, vol. 38, pp. 1-4.

TherRelL, M. D. et al. (2006). «Tree-ring Reconstructed Maize Yield in Central Mexico: 14742001», Climatic Change, vol. 74, pp. 493-504.

TorRes Rodríguez, E. et al. (2012). «Cambio ambiental y respuestas de la vegetación de los últimos 17,000 años en el centro de México: el registro del lago de Zirahuén», Revista Mexicana de Ciencias Geológicas, vol. 29, pp. 764-778.

Trabulse, E. (1985). Historia de la ciencia en México. 4 vols. México: Consejo Nacional de Ciencia y Tecnología / Fondo de Cultura Económica.

Trautmann, W. (1981). La transformación en el paisaje cultural de Tlaxacala durante la época colonial: una contribución a la historia de México bajo especial consideración de aspectos geográficos, económicos y sociales. Wiesbaden: F. Steiner.

TORTOLero, A. (2008). Notarios y agricultores. Crecimiento y atraso en el campo mexicano, 1780-1920. México: Siglo XXI / Universidad Autónoma Metropolitana.

VAN Young, E. (1981). Hacienda and Market in Eightienth Century Mexico: the Rural Economy of the Guadalajara Region, 1675-1820. Berkeley: University of California Press.

Viesca, C.; Sanfilippo, J. (2010). «La ciencia en el México independiente». En R. Pérez Tamayo. Historia de la ciencia en México. México: Fondo de Cultura Económica / Consejo Nacional para la Cultura y las Artes, pp. 43-119.

West, R. (1949). The Mining Community of Nothern New Spain: The Parral Mining District. Berkeley: University of California Press.

West, R. (1976). Las tierras bajas de Tabasco en el sureste de México. México: Gobierno del Estado de Tabasco. 